\title{
Influence of partial deletion of the $Y$ chromosome on mouse sperm phenotype
}

\author{
J. Styrna ${ }^{1}$, J. Klag ${ }^{2}$ and K. Moriwaki ${ }^{3}$ \\ Departments of ${ }^{1}$ Genetics and Evolution, and ${ }^{2}$ Zoology, Institute of Zoology, \\ Jagiellonian University, Karasia 6, 30-060 Krakow, Poland; and ${ }^{3}$ Department of Cell Genetics, \\ National Institute of Genetics Yata-1111, Mishima, Shizuoka, Japan
}

\begin{abstract}
Summary. Two congenic strains of mice (control, B10.BR/SgSn; mutant, B10.BR$\mathrm{Ydel} / \mathrm{Ms}$ with partial deletion of the $\mathrm{Y}$ chromosome) were examined. In control males, $22.6 \%$ of spermatozoa had abnormal heads; in mutant males, there were $64.2 \%$, the most common being heads with flat acrosomes. Sodium dodecyl sulphate polyacrylamide gel electrophoresis of mature sperm proteins, followed by acrosin assay and acrosome silver staining, revealed a reduced concentration of acrosin in acrosomal caps in $35.8 \%$ of the spermatozoa in mutant males. Electron microscope analysis showed that some of the round, early spermatids in the mutants had normally formed acrosomal caps but lacked the proacrosomal granule and had no, or only scarce, acrosomal material. These observations indicate that formation of the acrosomal cap is controlled separately from the synthesis of the acrosomal material and suggest that some factors linked on the $\mathrm{Y}$ chromosome are involved in the control of acrosome development.
\end{abstract}

Keywords: Y chromosome; abnormal spermatozoa; acrosomal development; mouse

\section{Introduction}

Studies of mutations which perturb the normal course of spermatogenesis can be useful for elucidating mechanisms of sperm differentiation and its genetic control. Several such mutations have been identified in mice (Bryan, 1977a, b; Sotomayor \& Handel, 1986; Cole et al., 1988). Most are pleiotropic, affecting processes other than spermatogenesis, but all cause sperm structural abnormalities, abnormalities in head shape being the most common.

We report a new mutation ( $\mathrm{Ydel}$ ) in mice, caused by partial deletion of the $\mathrm{Y}$ chromosome, as indicated by a reduction in size of this chromosome (Figs 1 and 2). The mutation was found during chromosome analysis of B10.BR/SgSn males from the Jackson Laboratory (Bar Harbor, ME, USA). The congenic strain to $\mathrm{B} 10 . \mathrm{BR} / \mathrm{SgSn}$ was developed from the mutant male, designated as the mutant Bl0.BR-Ydel/Ms and maintained, since 1977, in the National Institute of Genetics, Mishima, Japan.

The most evident effect of the Ydel mutation on spermatogenesis is the increased number of abnormal spermatozoa, particularly those with flat acrosomal caps. In this study, we compared sperm acrosomes of normal and mutant males, using morphological and biochemical analyses.

\section{Materials and Methods}

Mice. Normal B10.BR/SgSn mice were obtained from Shizuoka Laboratory Animal Center (Japan). The mutant strain is being maintained by back-crossing Bl0.BR-Ydel/Ms males to B10.BR/SgSn females, to avoid divergence between the congenic strains.

Reagents. Protein standards for sodium dodecyl sulphate (SDS) polyacrylamide gel electrophoresis were obtained from Bio-Rad Laboratories (Richmond, CA, USA); silver proteinate was purchased from Ebisu Pharmaceutical Co., Osaka, Japan. All other reagents were from Wako Pure Chemical Industries, Osaka, Japan. 
(a)

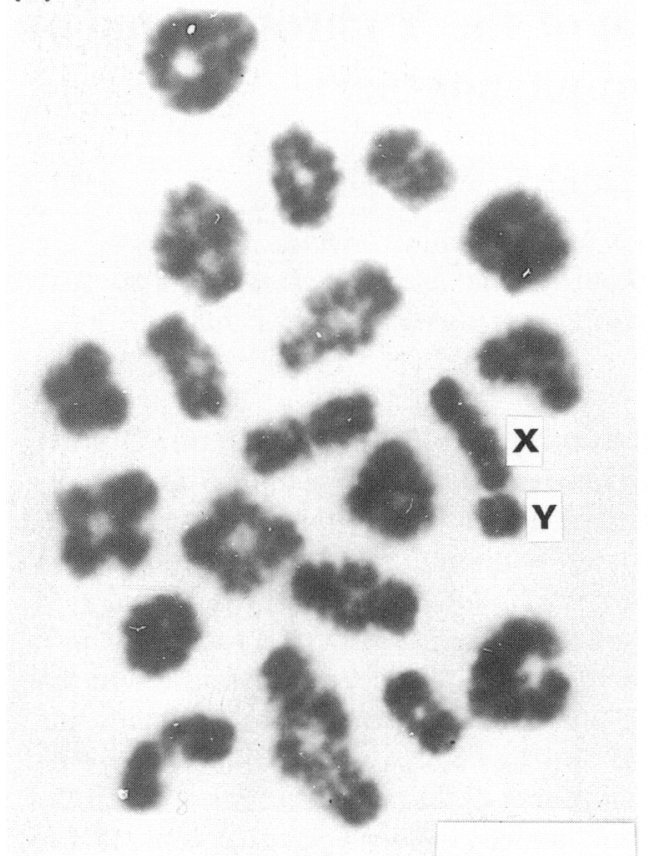

(b)

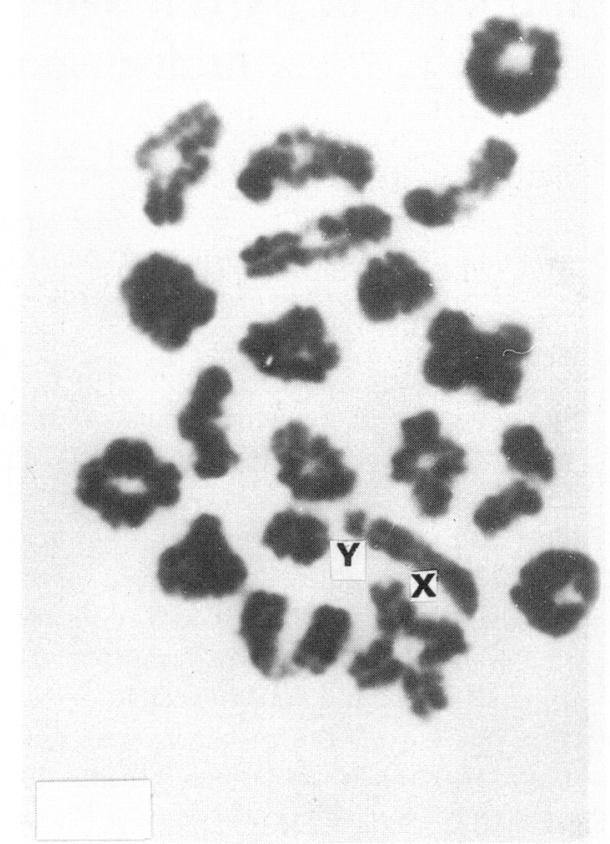

Fig. 1. Meiotic mouse chromosomes of (a) B10.BR/SgSn (normal) and (b) B10.BR-Ydel/Ms ( $Y$ del ) males. $\mathrm{X}$ and $\mathrm{Y}$ chromosomes are indicated.

Chromosome preparations. Five adult males of each strain were used. Mitotic chromosome spreads were made from bone marrow cells (Nomura et al., 1984); meiotic chromosome spreads were prepared from testes (Meredith, 1969).

Sperm morphology. Fifteen males of each strain were killed by cervical dislocation, and smears of spermatozoa were prepared from the contents of the vasa deferentia. The preparations were stained with eosin- $Y$ and examined with an Olympus microscope at $\times 65$. For each male, 200 spermatozoa were counted and the percentage of abnormal heads was determined. The classification of abnormal forms was based on those described by Krzanowska (1974). with a slight modification: Class I was divided into subclasses $a$ and $b$, subclass $b$ being specific for the Ydel mutation and characterized by flattening of the acrosomal cap (Fig. 3).

Protein composition of mature spermatozoa. Washed spermatozoa from the cauda epididymidis and vas deferens were fractionated into three components (SDS-soluble proteins, tail fraction and head fraction) according to the protocol of O'Brien \& Bellvé (1980a). The tail component was solubilized in $0 \cdot 1 \mathrm{M}$ dithiothreitol (DTT) and 0.1M Tris: $\mathrm{HCl}(\mathrm{pH} 7 \cdot 4)$. Solubilization and purification of the head proteins was carried out according to the procedure of Bellvé et al. (1975). Dissociation medium contained 4M guanidine hydrochloride, 50mM EDTA, Imm phenylmethyl sulphonyl fluoride (PMSF) and 0.5 $\mathrm{M}$ Tris: $\mathrm{HCl}(\mathrm{pH} \mathrm{8.6)}$. SDS-soluble proteins and tail proteins were subjected to electrophoresis on SDS-polyacrylamide slab gels as described by Laemmli (1970). Basic proteins from the SDS-insoluble head fraction were analysed on acetic-acid-urea polyacrylamide slab gels (pH 2.7) (Bellvé et al., 1975).

Acrosomal proteinase activity. For acrosin assay, epididymides from mice $\sim 4$ months old were sliced under $0 \cdot 25 \mathrm{M}$ sucrose solution. The suspension was filtered through Nitex nylon cloth (130- $\mu \mathrm{m}$ mesh) to remove tissue debris, and acrosin was extracted from the spermatozoa according to the method of Brown \& Hartree (1976). Acrosin activity was measured by the hydrolysis of $N$-benzoyl-L-arginine ethyl ester (BAEE) at $25^{\circ} \mathrm{C}$. The assay mixture contained $0.05 \mathrm{M}$ Tris: $\mathrm{HCl}(\mathrm{pH} 8 \cdot 2), 0 \cdot 2 \mathrm{M}-\mathrm{CaCl}_{2}$ and BAEE. Enzyme activity is given in $\mathrm{nmol} / \mathrm{min} / 10^{7}$ spermatozoa.

Spermatozoa for silver staining were collected from the cauda epididymidis and suspended in Tyrode's solution. A drop of dense sperm suspension was spread over a clean slide and quickly air dried. Prepared sperm smears were fixed and incubated in the substrate mixture containing $1 \%$ silver proteinate, according to the method of Yanagimachi \& Teichman (1972).

Ultrastructural analysis of spermatids. Testicular tissue for ultrastructural analysis was fixed in $2 \cdot 5 \%$ osmium tetroxide $\left(\mathrm{OsO}_{4}\right)$ in phosphate buffer $(\mathrm{pH} 7 \cdot 4)$ for $3 \mathrm{~h}$ at room temperature, fixed in $1 \% \mathrm{OsO}_{4}$ in the same buffer, 

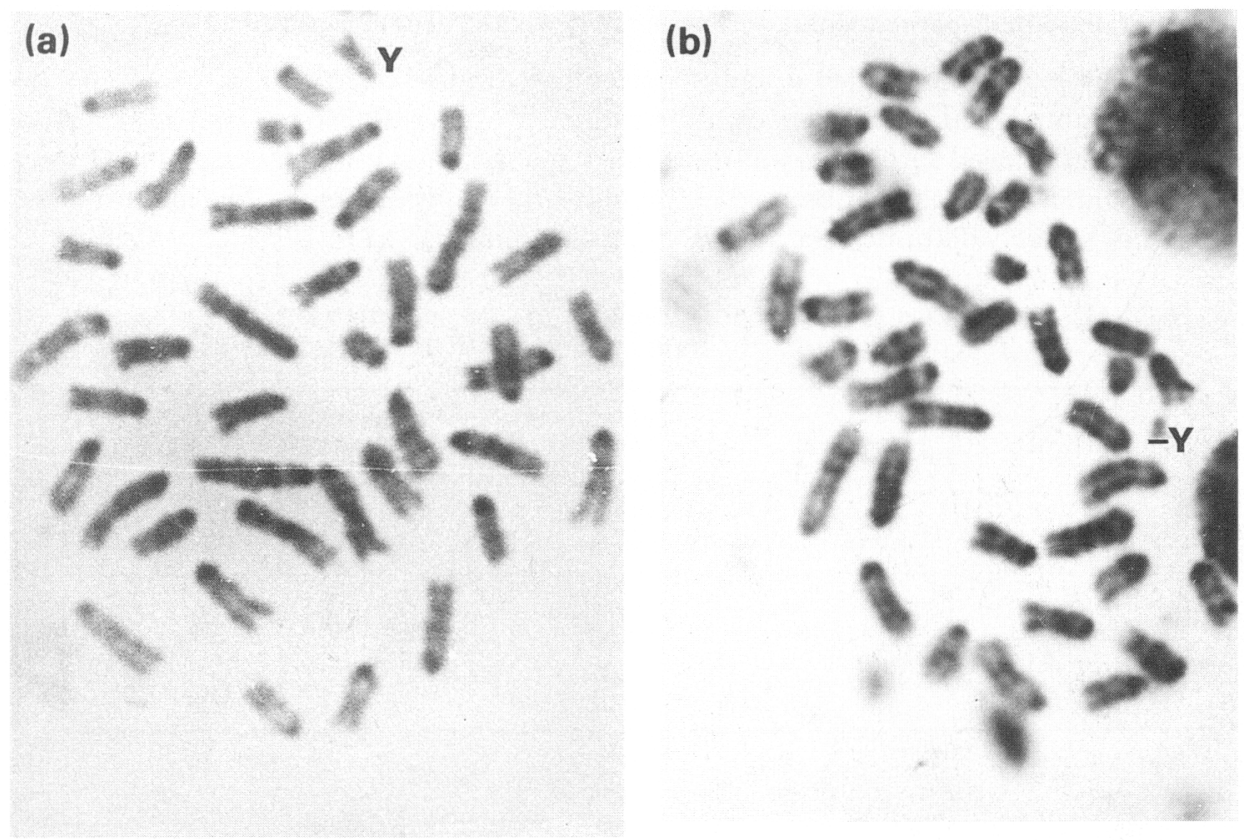

Fig. 2. Mitotic mouse chromosomes plates of (a) B10.BR/SgSn (normal) and (b) B10.BR-Ydel/ Ms ( $Y$ del ) males. Normal and reduced-size Y chromosomes are indicated. Staining was by G-banding.

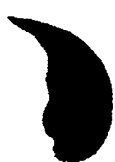

Normal

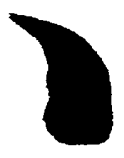

$1 \mathrm{a}$

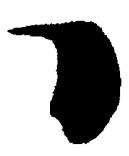

$1 \mathrm{~b}$

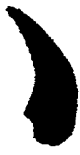

2

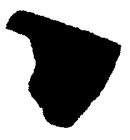

3

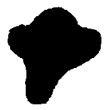

4

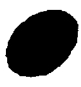

5

Fig. 3. Morphology of normal and abnormal mouse sperm heads divided into 5 classes (from Krzanowska, 1974). Class 1 b is specific for Ydel mutant males.

dehydrated in ethanol and acetone and embedded in Epon 812. Thin serial sections were cut with a Tesla BS 490A ultratome, stained with uranyl acetate and lead citrate and examined and photographed using a Tesla BS 500 electron microscope.

\section{Results}

\section{Chromosome analysis}

The lengths of the Y chromosome and of the smallest chromosome (No. 19) were measured on 5 mitotic chromosome spreads of different males. At least 20 chromosome plates were scored for each individual. The ratio of Y normal:chromosome 19 was $1.05(1.0-1.09)$; the ratio of Y-del: chromosome 19 was $0 \cdot 24(0 \cdot 21-0 \cdot 28)$.

From each strain, 50 spermatocytes at first meiotic metaphase were examined to estimate the percentage of dissociated $\mathrm{X}-\mathrm{Y}$ chromosomes, which was $8.3 \pm 2 \cdot 1 \%$ for normal and $8.5 \pm 2.9 \%$ for mutant males. 


\section{Percentage of abnormal spermatozoa}

Males of the mutant strain had a higher percentage of misshapen spermatozoa $(64 \cdot 2 \%)$ than normal mice (Table 1) and the frequency of abnormality classes differed: class $1 \mathrm{~b}$, with an almost normal head but flattened acrosome, was the most frequent in mutant males, accounting for $44.5 \%$ of all abnormalities, but was not observed in spermatozoa of normal males. The mutant had higher proportions of severely deformed spermatozoa (classes 2 and 4 ).

Table 1. Proportions of sperm abnormalities in 200 spermatozoa of normal and mutant mice

\begin{tabular}{|c|c|c|c|c|c|c|c|c|}
\hline \multirow[b]{3}{*}{ Strain } & \multirow[b]{3}{*}{$n$} & \multicolumn{7}{|c|}{ Mean $\%$ of abnormal spermatozoa } \\
\hline & & \multicolumn{5}{|c|}{ Class of abnormality* } & \multirow[b]{2}{*}{5} & \multirow{2}{*}{$\begin{array}{c}\text { Total \% } \\
\text { Mean } \pm \text { s.d. }\end{array}$} \\
\hline & & la & $1 \mathrm{~b}$ & 2 & 3 & 4 & & \\
\hline $\begin{array}{l}\mathrm{B} 10 . \mathrm{BR} / \mathrm{SgSn} \\
\text { (normal) }\end{array}$ & 15 & $0 \cdot 8$ & 0 & $2 \cdot 0$ & $12 \cdot 2$ & $7 \cdot 5$ & 0.1 & $22 \cdot 6 \pm 2 \cdot 4$ \\
\hline $\begin{array}{l}\text { (mutant) } \\
\text { (molis }\end{array}$ & 15 & 0 & $28 \cdot 5$ & 7.5 & 14.3 & $13 \cdot 8$ & 0 & $64 \cdot 2 \pm 7 \cdot 7$ \\
\hline
\end{tabular}

*See Fig. 3.

\section{Sperm protein analysis}

Proteins of the SDS-soluble fraction are probably derived from the plasma membrane, acrosome, axoneme and mitochondria (O’Brien \& Bellvé, 1980a). In normal males, this fraction contained a wide range of proteins with $M_{\mathrm{r}}$ of 14000-150000 (Fig. 4). The major protein in this fraction, as assessed by Coomassie Brilliant Blue stain, had $M_{\mathrm{r}} \sim 39000$ and might have been proacrosin (O'Brien \& Bellvé, 1980a). In the mutants, this component was clearly reduced. Analysis of tail and head proteins, under the conditions used in this study, did not reveal any differences between the strains (data not presented).

\section{Acrosin assay}

For each assay, spermatozoa were pooled from three males of the given strain. Each experiment was repeated 10 times. The mean $\pm \mathrm{s} . d$. total acrosin $\left(\mathrm{nmol} \mathrm{BAEE}\right.$ hydrolysed $/ \mathrm{min} / 10^{7}$ spermatozoa) was $51.0 \pm 1.05 \mathrm{nmol}$ for normal males and $29.0 \pm 0.91$ for mutant males.

\section{Cytochemical demonstration of acrosin activity in mature spermatozoa}

Using the histochemical method of Yanagimachi \& Teichman (1972), the proteolytic action of acrosin, a trypsin-like protease, was visualized by a dark brown-black precipitate of silver released from silver proteinate by the enzyme. As shown in Fig. 5, enzyme activity appeared along the acrosomal caps. In normal males, almost all acrosomes showed a strong silver reaction even in distorted sperm heads (Fig. 5a), but $35 \cdot 77 \pm 3.7 \%$ of spermatozoa from mutant males did not show silver staining (Fig. 5b).

\section{Ultrastructure of spermatids}

Electronmicrographs of spermatocytes and early spermatids of mutant males did not appear to differ from those of normal males, but differences were observed between the strains during the Golgi phase. In normal males, a well-organized Golgi complex with developing proacrosomic vesicles occurred in proximity to a spermatid nucleus. The proacrosomic vesicles fuse to form the 
(a) (b)

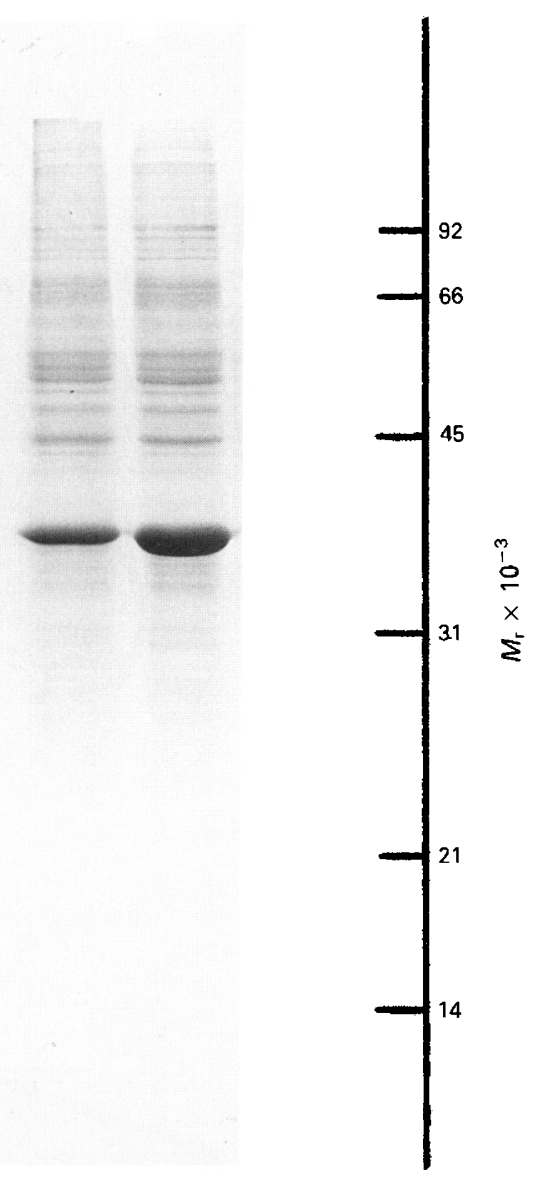

Fig. 4. SDS-soluble fraction of mouse spermatozoa following SDS-polyacrylamide gel electrophoresis. (a) $Y$ del male, (b) normal male. Standards used for $M_{\mathrm{r}}$ determinations include phosphorylase B (92500), bovine serum albumin (66 200), ovalbumin (45500) carbonic anhydrase (31 000), soyabean trypsin inhibitor (21500) and cytochrome c (14000).

acrosomal granule, which becomes associated with the nucleus. In the region of this association, the nuclear membrane was more electron-dense and appeared slightly thickened (Fig. 6a). In the mutants amongst normally developed spermatids (Fig. 6b, spermatid c) some spermatids were less well organized, in that the acrosomal vesicle had formed, but there was no acrosomal granule (Fig. $6 \mathrm{~b}$, spermatid d). However, most of the spermatids that lacked acrosomal granules had a welldeveloped Golgi apparatus (Fig. 7a), suggesting that the lack of an acrosomal granule is not related to structural abnormality of the Golgi complex. Some small proacrosomal granules were seen but they did not fuse with the acrosomal vesicle (Figs $7 \mathrm{~b}, \mathrm{~d}$ ), or only a little electron-dense material appeared in the acrosomal vesicle (Fig. 7c). A consequence of this defect was seen in older spermatids (see Fig. 7e, showing an empty acrosome).

\section{Discussion}

The $\mathrm{Y}$ chromosome in mice encodes information for testis determination, $\mathrm{H}-\mathrm{Y}$ antigen production and spermatogenesis (Cattanach et al., 1971; Singh \& Jones, 1982; Levy \& Burgoyne 1986). 

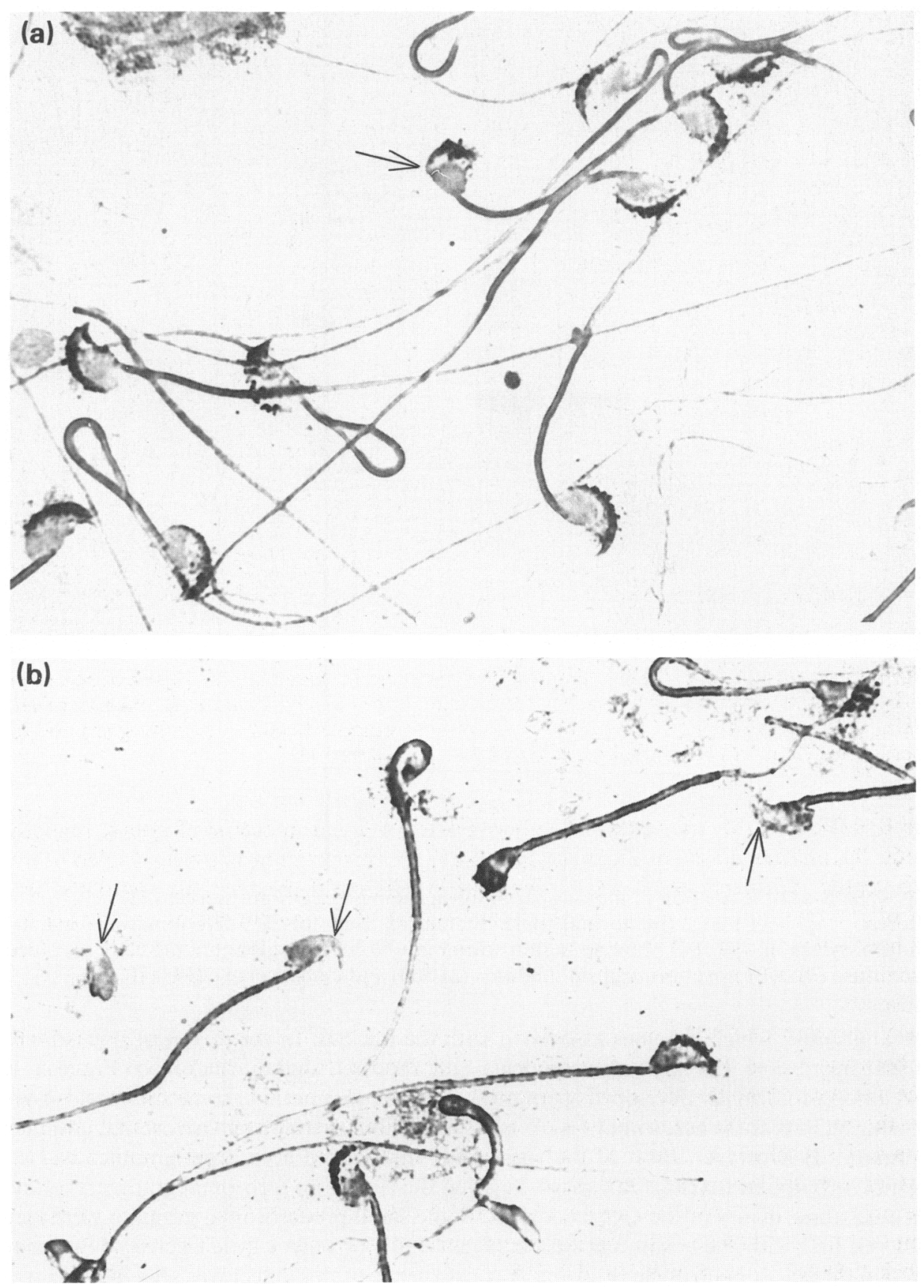

Fig. 5. Reaction products of silver proteinate and acrosomal proteinase in the acrosomes of (a) normal male mice (arrow shows silver staining in distorted sperm head) and (b) the absence of proteinase activity (arrows) in acrosomes of mutant males; $(Y d e l) \times 2200$. 

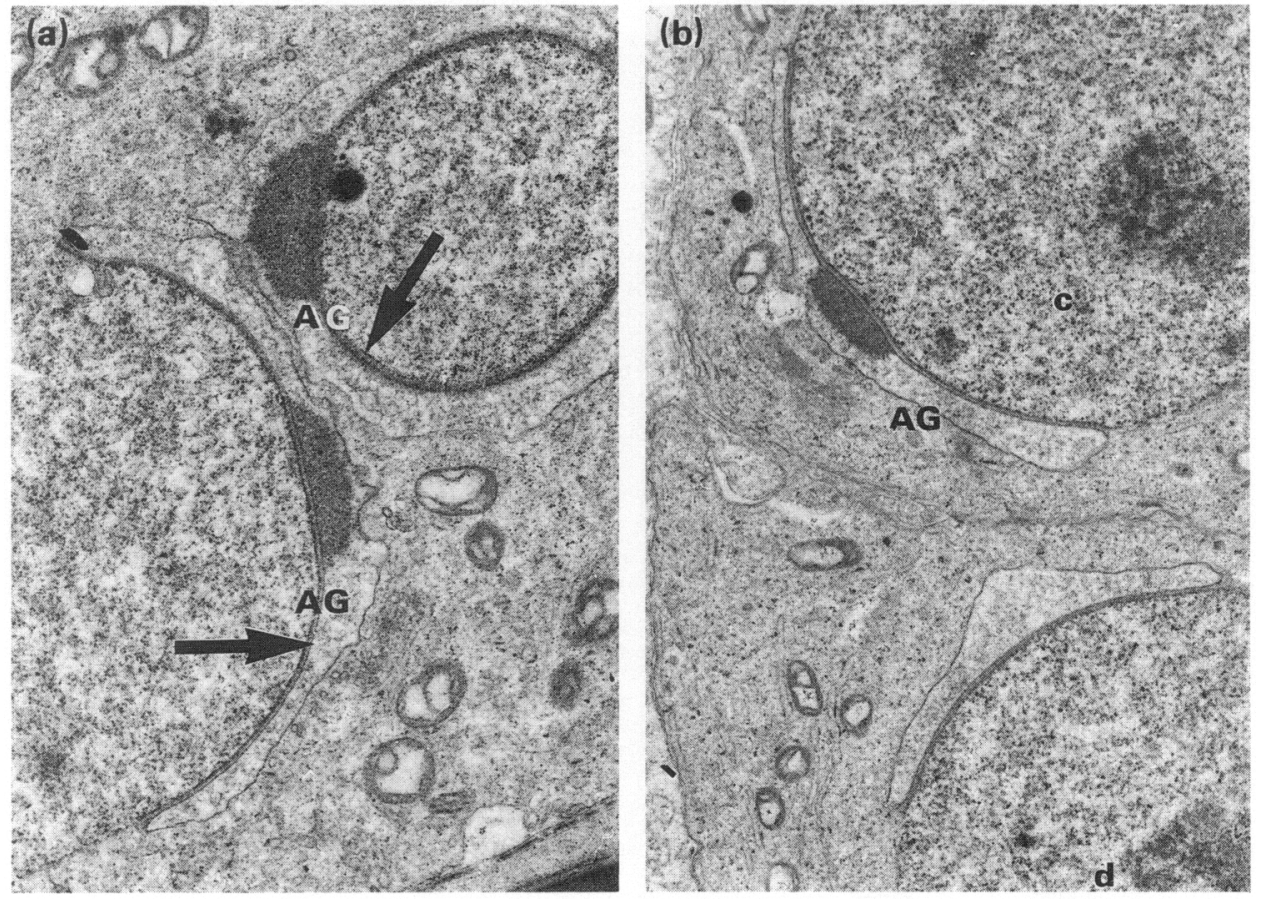

Fig. 6. Early spermatids of (a) normal male mice showing the normal development of acrosome with the more electron-dense nuclear membrane (arrow) $\times 9500$ and (b) mutant $(Y$ del $)$ males showing variations in the organization of acrosome; $\times 10600 ; \mathrm{c}$, normal spermatid, $\mathrm{d}$, spermatid without an acrosomal granule (AG).

The B10.BR-Ydel/Ms males described here possess a Y chromosome of clearly reduced size. Theoretically, one could assume that a fragment of the $\mathrm{Y}$ chromosome has been deleted or translocated to another chromosome. However, translocation should be excluded, because of the breeding system of the congenic strains. Continuous back-crossing of mutant males to normal females should have eliminated any translocated chromosome even if it had been originally involved. All abnormalities observed in the mutant males are probably due to the lack of part of the $Y$ chromosome.

The $\mathrm{Y}$ chromosome in the mutant should possess the pseudoautosomal region because conjugation between $\mathrm{X}$ and $\mathrm{Y}$ chromosomes seems to be normal (Fig. 1). The fact that mutant males produce functional spermatozoa indicates that the deletion on the $\mathrm{Y}$ chromosome does not include the regions necessary for testis determination and spermatogenesis. However, the high percentage of sperm abnormalities in mutant males suggests that some factors influencing normal spermatogenesis are lacking or incomplete.

The predominant abnormality type, characterized by flat acrosomes, seems to be specific to these mutant males; it has not, to our knowledge, been observed in any other mouse strains tested (Wyrobek \& Bruce, 1975; Kot \& Handel, 1987).

Our results revealed reduced activity of acrosin in some acrosomal caps of mutant males, and electron microscope analysis showed that some of the early spermatids lack proacrosomal granules, although they had normally formed acrosomal caps. This suggests that the formation of the caps is controlled separately from the synthesis of acrosomal material.

The disturbance of acrosome development during spermiogenesis in mice is known to be caused by a series of autosomal genes. In mice homozygous for the recessive $p^{\mathrm{s}}$ allele (pink-eyed, sterile mutation), various abnormalities appear during acrosome formation, ranging from atypical Golgi 

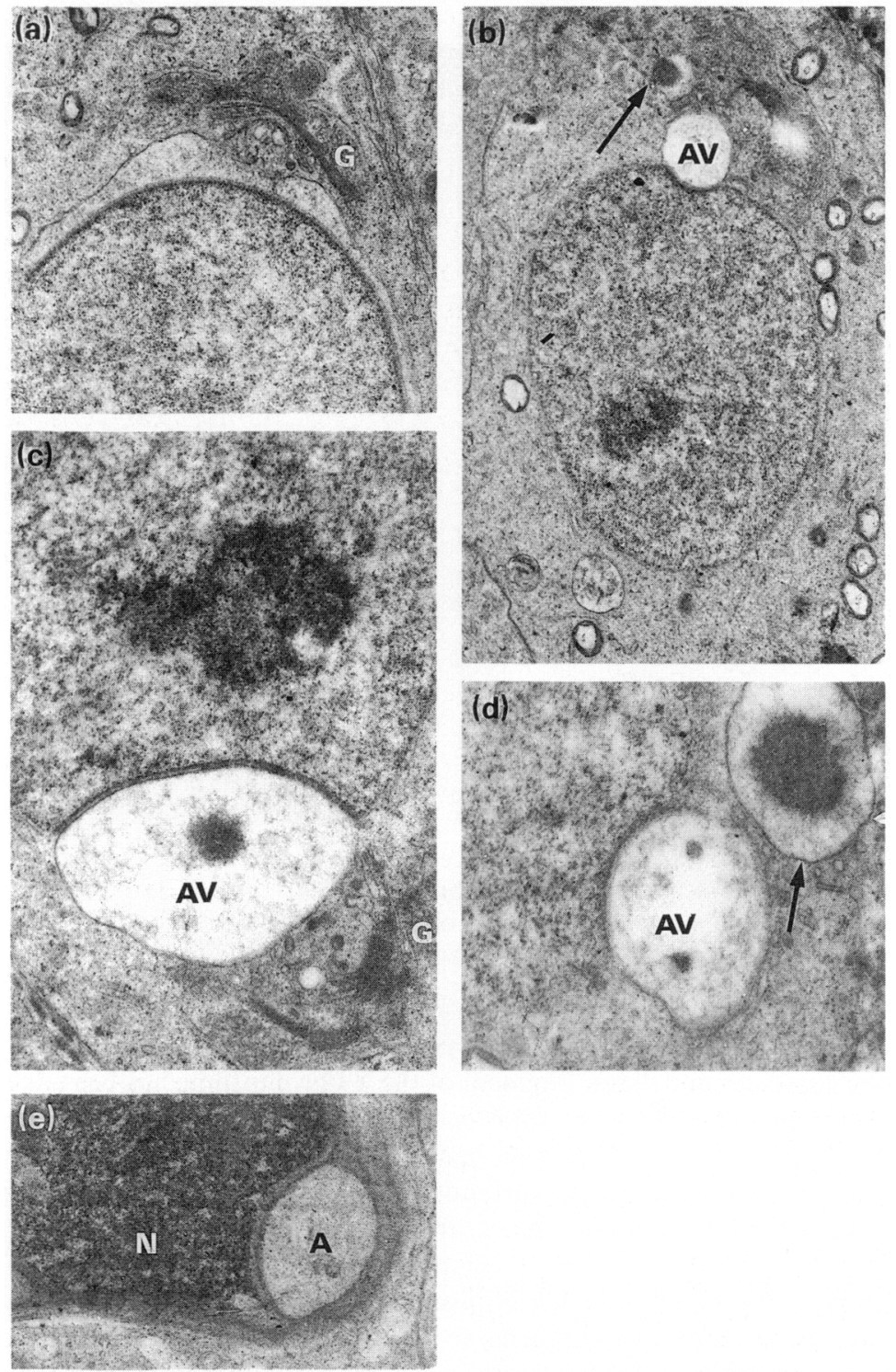

Fig. 7. Spermatids of mutant ( $Y$ del) mice. (a) Golgi apparatus (G) associated with an empty acrosomal vesicle, $\times 12000$; (b) nucleus showing developing acrosomal vesicle (AV) without an acrosomal granule. A small proacrosomal granule which does not fuse with acrosomal vesicle is indicated by the arrow, $\times 7500$; (c) acrosomal vesicle containing a small amount of acrosomal material, $\times 18000 ;$ (d) proacrosomal granule (arrow) which does not fuse with acrosomal vesicle, $\times 22000$; (e) absence of acrosomal material, $\times 14500$; A, acrosome; N, nucleus.

acrosome complexes to multiple-acrosome 'implantation' sites on spermatid nuclei. The proacrosomal vesicles do not form acrosomal granules. This may be a result of low production of acrosomal material or a failure of proacrosomal vesicles to fuse to form the acrosomal granule (Bryan, 1977a).

The gene $b s$ (for blindness and sterility) on chromosome 2 causes complete failure of the acrosome complex. Most $b s, b s$ mice have no spermatozoa in the epididymis or the vas deferens and the other mutants have fewer than normal spermatozoa. The spermatozoa that are produced are 
unmotile and greatly deformed. The anterior (acrosomeless) part of the sperm nucleus is particularly misshapen. Sotomayor \& Handel (1986) consider this as evidence that acrosome formation or the acrosome itself can play an active role in determinating nuclear shape. Mice heterozygous for 2 lethal $t$ haplotypes $t^{0} / t^{\mathrm{w} 32}$ linked on chromosome 17 demonstrate various developmental defects involving the failure of the acrosome to maintain normal attachment to the nucleus (Gill et al., 1983). The mechanism by which these genes influence acrosomal development is not known, but Shur \& Bennett (1979) reported a change in enzyme activity in the mutant spermatozoa.

The results presented here indicate that the $\mathrm{Y}$ chromosome is involved in development of the acrosome, one of the most important components of the sperm cell. However, Y-linked factors are unlikely to influence the synthesis of each enzyme in the acrosomal cap, but are more likely to control the co-ordination of various synthetic and morphogenetic processes during critical phases of spermatid development, as suggested by Meyer (1972) in the Drosophila Y chromosome. Autosomal genes giving similar acrosomal defects can contribute primary structural information, and can be sensitive to regulatory function of the $\mathrm{Y}$ chromosome.

We thank Professor H. Krzanowska for critical review and helpful comments on the manuscript. This work was partly supported by the Polish Academy of Sciences within the project CPBP.05.05.

\section{References}

Bellvé, A.R., Anderson, E. \& Hanley-Bowdoin, L. (1975) Synthesis and amino acid composition of basic proteins in mammalian sperm nuclei. Devl Biol. 47, 349-365.

Brown, C.R. \& Hartree E.F. (1976) Identification of acrosin in mouse spermatozoa. J. Reprod. Fert. 46, 249-251

Bryan, J.H.D. (1977a) Spermatogenesis revisited. III. The course of spermatogenesis in a male-sterile pinkeyed mutant type in the mouse. Cell Tiss. Res. 180, $173-186$

Bryan, J.D.H. (1977b) Spermatogenesis revisited. IV. Abnormal spermatogenesis in mice homozygous for another male sterility-inducing mutation, hpy (hydrocephalic-polydactyl). Cell Tiss. Res. 180, 187--201.

Cattanach, B.M., Pollard, C.E. \& Hawkes, S.G. (1971) Sex reversal mice: $\mathrm{XX}$ and $\mathrm{X} 0$ males. Cytogenetics 10 , 318-337.

Cole, A., Meistrick, M.L., Cherry, L.M. \& TrostleWeige, P.K. (1988) Nuclear and manchette development in spermatids of normal and $a z h / a z h$ mutant mice. Biol. Reprod. 38, 385 401 .

Gill, T.J.III, Siew, S., Kunz, H.W. (1983) Major histocompatibility complex (MHC)-linked genes affecting development. J. exp. Zool. 228, 325-345.

Kot, M.C., Handel, M.A. (1987) Binding of morphologically abnormal sperm to mouse egg zonae pellucidae in vitro. Gamete Res. 18, 57-66.

Krzanowska, H. (1974) The passage of abnormal spermatozoa through the uterotubal junction of the mouse. J. Reprod. Fert. 38, 81-90.

Laemmli, U.K. (1970) Cleavage of structural proteins during the assembly of the head of bacteriophage $T_{4}$. Nature, Lond. 227, 680-685.

Levy, E.D. \& Burgoyne, P.S. (1986) The fate of X0 germ cells in the testes of $\mathrm{X} 0 / \mathrm{XY}$ and $\mathrm{X} 0 / \mathrm{XY} / \mathrm{XYY}$ mouse mosaics: evidence for a spermatogenesis gene on the mouse Y chromosome. Cytogenet. Cell Genet. 42, $208-213$.

Meredith, R. (1969) A simple method for preparing meiotic chromosomes from mammalian testis. Chromosoma 26, 254-258.

Meyer, G.F. (1972) Influence of Y chromosome on fertility and phenotype of Drosophila spermatozoa. In The Genetics of the Spermatozoon, pp. $387-405$. Eds R. A. Beatty \& S. Gluecksohn-Waelsch. R. A. Beatty \& S. Gluecksohn-Waelsch, Edinburgh.

Nomura, T., Esaki K., Tomita T. (1984) Preparation of slides for chromosome observation. In ICLAS Manual for Genetic Monitoring of Inbred Mice, pp. 150-161. Eds T. Nomura, K. Esaki \& T. Tomita. University of Tokyo Press.

O'Brien, D.A. \& Bellvé, A.R. (1980a) Protein constituents of the mouse spermatozoon. I. An electrophoretic characterization. Devl Biol. 75, 386-404.

Shur, B.D. \& Bennett, D. (1979) A specific defect in galactosyl transferase regulation in sperm bearing mutant alleles of the $T / t$ locus. Devl Biol. 71, 243-259.

Singh, L. \& Jones, K.W. (1982) Sex reversal in the mouse (Mus musculus) is caused by a recurrent nonreciprocal crossover involving the $\mathrm{X}$ and an aberrant $\mathrm{Y}$ chromosome. Cell 28, 205-216.

Sotomayor, R.E. \& Handel, M.A. (1986) Failure of acrosome assembly in a male sterile mouse mutant. Biol. Reprod. 34, 171-182.

Wyrobek, A.J., Bruce, W.R. (1975) Chemical induction of sperm abnormalities in mice. Proc. natn. Acad. Sci. U.S.A. 72, 4425-4429.

Yanagimachi, R. \& Teichman, R.J. (1972) Cytochemical demonstration of acrosomal proteinase in mammalian and avian spermatozoa by a silver proteinate method. Biol. Reprod. 6, 87-97.

Received 3 August 1990 